\title{
Cancer Stem Cells: Prospective Isolation and Progress Toward Functional Biomarker Identification
}

\author{
Stefan Rentas • Nicholas Holzapfel • \\ Kristin Hope
}

Published online: 26 March 2013

(C) Springer Science+Business Media New York 2013

\begin{abstract}
With the emergence of the cancer stem cell hypothesis in leukemia there has been a need to develop the crucial tools and assays to prospectively isolate these cells from other cancers. This review focuses on the latest strategies to prospectively isolate cancer stem cells and also explores some of the caveats of the methodology that has taken hold. Emerging themes in the cancer stem cell field will be explored, including relevance of cell of origin, intraclonal heterogeneity, and how exploiting the unique functional attributes of stemness in the cancer stem cell population can refine approaches to isolate these cells from various malignancies.
\end{abstract}

Keywords Cancer stem cell - CSC - Stem cell - Tumor initiating cell · Prospective isolation - Immunophenotype . Xenotransplant · Tumor heterogeneity - Clonal evolution . Biomarkers · Pathobiology

\section{Introduction}

Cancers are comprised of genetically, phenotypically and functionally heterogeneous cell populations, yet it is also known that they are clonal in their nature [1]. The coexistence of the seemingly mutually exclusive features of

S. Rentas · N. Holzapfel · K. Hope $(\bowtie)$

Department of Biochemistry and Biomedical Sciences, Stem Cell and Cancer Research Institute, McMaster University, 1280 Main Street West, Hamilton, ON L8S 4K1, Canada e-mail: kristin@mcmaster.ca

S. Rentas

e-mail: srentas@mcmaster.ca

N. Holzapfel

e-mail: nicholas.holzapfel@medportal.ca heterogeneity and clonality in individual malignancies can be reconciled by the cancer stem cell (CSC) hypothesis [2]. This hypothesis suggests that neoplasms are organized as cellular hierarchies and that initiation and maintenance of growth in a given cancer is carried out by a unique and usually infrequent subset of CSCs. A central tenet of this model is that it must be possible to prospectively isolate a subset of the cancer population that has the unique capacity (not shared by the bulk of the cancer) to initiate and propagate the disease. In this respect, the CSC model hypothesizes a structure in cancer that is analogous to the hierarchal organization of normal tissues [3], such as the hematopoietic system, where blood cell production is maintained by phenotypically and functionally unique hematopoietic stem cells (HSC) that divide into increasingly lineage-restricted intermediates which ultimately differentiate into mature cells. In the CSC model, instead of contributing normal functioning differentiated cells for tissue homeostasis, CSCs drive deregulated clonal expansion of non-tumor initiating neoplastic cells that are phenotypically and functionally diverse. With the introduction of the CSC hypothesis and the seminal discovery of CSCs in acute myeloid leukemia (AML) [4, 5], there has been great interest over the last decade to develop the crucial tools and assays to prospectively isolate these cells from other cancers. Historically, prospective isolation was essential for the first validation that a given cancer conforms to the CSC model. At the present time however, interest has turned to refinement of these isolation parameters in order to more precisely pinpoint the CSC population so that we might better define its molecular state and thus develop more targeted and effective therapies. Advances that would allow rare CSCs to be conclusively identified are also sought in order to facilitate the characterization of their behavior in situ. The realization that 
CSCs are also dynamic entities subject to evolutionary changes previously thought to be manifest by more downstream cell types is a very recent finding. This discovery has meant that prospective isolation of multiple CSC subclones within single cancers can also provide important information on crucial genetic and epigenetic drivers of cancer progression.

In this review we will discuss the current state of prospective CSC isolation and the various strategies that are used to facilitate this. We will also highlight recent concepts and emerging controversies in the field that will necessitate consideration as more and more efforts are put into achieving true CSC purification from an increasing array of human malignancies. Lastly we will explore some of the novel approaches that are beginning to address the issue of prospective isolation by exploiting the unique functional attributes of stemness in CSC populations.

\section{Identification of Cancer Stem Cells}

\section{A Historical Perspective}

Studies involving human AML demonstrated the first direct evidence for the existence of CSCs [4, 5]. This work showed that the cell population marked by the surface marker phenotype $\mathrm{CD} 34^{+} \mathrm{CD} 38^{-}$, which is where normal HSCs reside, was the only population capable of giving rise to AML in non-obese diabetic severe immune deficient (NOD-SCID) mice. The AML engrafted in these mice resembled the original leukemia and could be serially transplanted. These initial studies provided the first direct evidence for the hierarchical organization of cancer with leukemic stem cells (LSC) at the apex of a dysregulated developmental hierarchy, and established the NOD-SCID xenotransplantation assay as the model of choice to test the CSC paradigm in other cancers.

The first identification of CSCs from a solid tumor was the discovery of a specific population of human breast cancer cells that were able to give rise to tumors in NODSCID mice [6]. Specifically, as few as $100 \mathrm{CD} 44^{+} \mathrm{CD} 24^{-/ 10}$ breast cancer cells were able to initiate tumors in the fat pads of immunocompromised mice, yet tens of thousands of the remaining cells were unable to form tumors. Notably, these tumors could be serially transplanted giving rise to further populations of $\mathrm{CD} 44^{+} \mathrm{CD} 24^{-/ \mathrm{lo}}$ tumor initiating cells (TIC) as well as phenotypically diverse non-TICs, providing distinct evidence for a specific self-renewing population with the capability of also recapitulating the heterogeneity of the original tumor. With this demonstration that CSCs exist in a neoplasm other than leukemia, the entry of those into the search for CSCs in other cancers was rapid. The CD133 ${ }^{+}$ glioblastoma and medulloblastoma cells were next identified as CSCs with the use of neurosphere assays and xenograft transplantation [7, 8]. At the present time, exhaustive testing for CSCs through trial and error exploration of the ability of surface markers as well as specific cellular functions to enrich for CSCs has culminated in evidence for their existence in other cancers including colon [9], pancreatic [10, 11], head and neck [12], and liver [13] (Table 1).

The State of the Art

There currently exist three standard methods by which CSCs are routinely enriched for. These consist of isolating cells (i) based on the presence and/or absence of a specific combination of cell surface markers, also known as immunophenotyping, (ii) based on their capacity to efflux Hoechst 33342 and (iii) based on the activity of the enzyme aldehyde dehydrogenase (ALDH). Of these approaches, immunophenotyping has been relied on most heavily, but typically involves a fairly iterative process, the first step of which is the attempt to purify based on marker expression identified in other cancer types or based on the known phenotype of the analogous tissue stem cell. In some cases, the use of negative selection for markers found upregulated in the bulk tumor actually improves the separation [6]. The further refinement of immunophenotypes is also often achieved by incorporating antibodies against additional surface antigens detected as differentially expressed in modestly CSC-enriched subsets [14]. It is important to note that in the above cases immunophenotypes that can substantially purify CSC populations are arrived at by significant trial and error attempts, each time requiring purification then lengthy transplantation assays before CSCs are or are not read out.

The enhanced ability of tissue stem cells to efflux the dye Hoechst 33342, and to therefore be isolatable in what was termed the "side population (SP)" or Hoechst ${ }^{\text {low }}$ subset was first shown in the murine hematopoietic system by Goodell and colleagues [15]. This capacity was later traced to the elevated expression of multidrug $\mathrm{ABC}$ membrane transporters [16]. The SP phenotype has since been applied to multiple cancers, and, in some cases, can enrich for the fraction of cells that has tumor initiating capacity [17]. Though this particular method of prospectively isolating CSCs is attractive in that it appears to be capitalizing on a presumably important mechanism of drug resistance that the CSC subset has uniquely exploited, caveats remain. Critics of the approach, for instance, suggest that toxicity may be an issue for the cells that cannot efflux efficiently, thus precluding their engraftment potential.

Finally, the use of ALDH activity to separate out CSCs is a fairly recent development. ALDHs irreversibly catalyze 


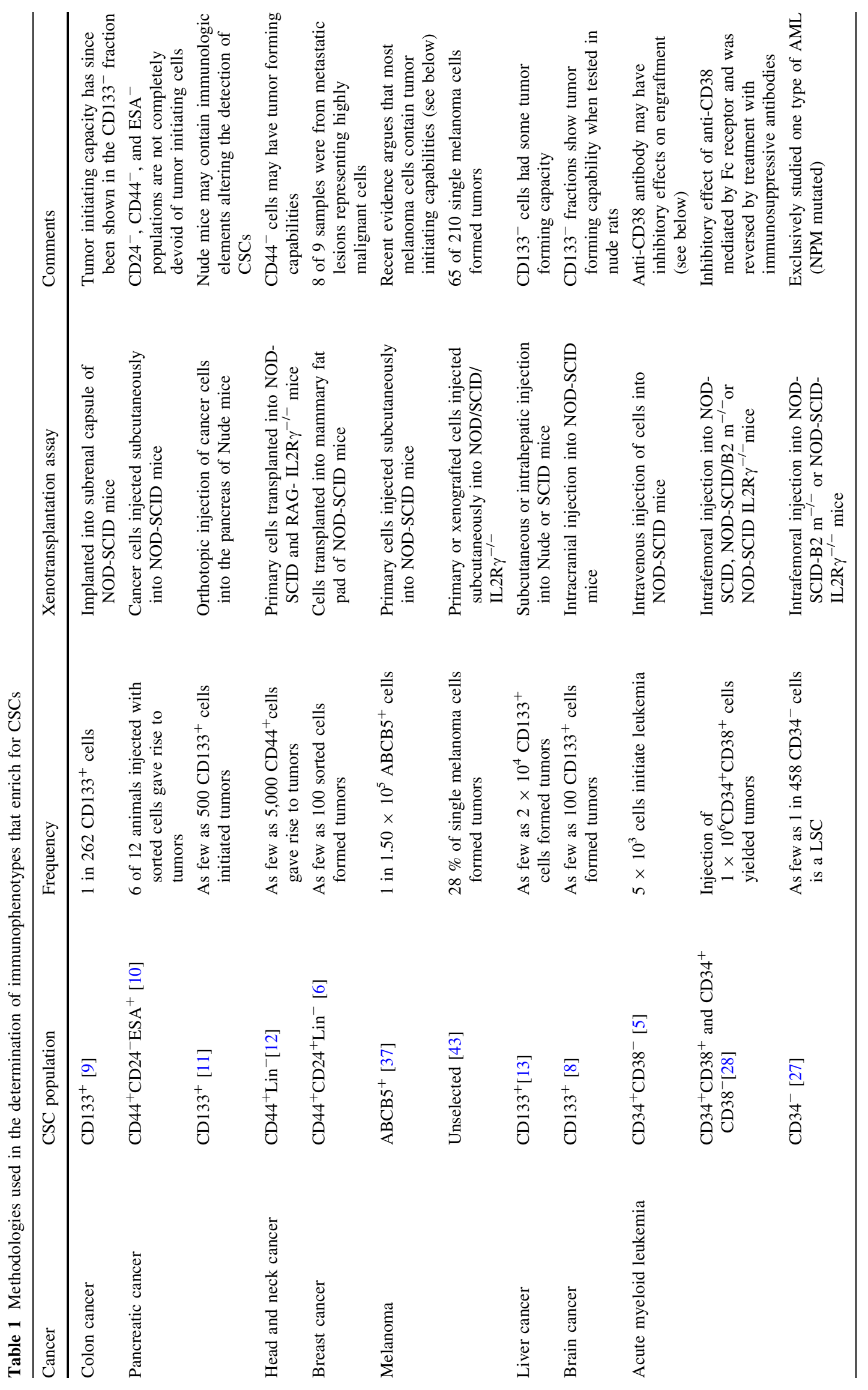


the conversion of cellular aldehydes to their corresponding acid form. Detection of cells expressing ALDHs can be achieved using the ALDEFLUOR dye which is oxidized by these enzymes leading to the accumulation of a fluorescent product [18]. As well as specifying normal stem cell populations $[18,19]$, ALDH activity has been found to be associated with CSC subsets in multiple leukemias and solid tumor types [20, 21]. Importantly, this method of separation, similarly to Hoechst efflux, relies on a functional capacity inherent for the more primitive cells of a cancer, but, in contrast, is not thought to impart toxicity to the labeled cells. The precise role of ALDHs in stem cell and CSC populations remains to be determined, though it is hypothesized that since ALDH oxidizes intracellular vitamin A to produce retinoic acid [22] this could promote signaling through various retinoic acid receptors (RAR) [23]. The role of RARs in cancer is complex, since loss of function, overexpression or mutation results in deregulation of normal tissue self renewal and differentiation programs [23]. Additionally, Aldh2 activity has been shown to protect HSCs from DNA damage due to accumulated acetaldehydes [24, 25]. Thus, the role of ALDH in RAR signaling and as a detoxifying enzyme of intracellular metabolites implicates its pleiotropic cellular effects. This will be important to consider before fully appreciating how ALDH can effectively mark various CSCs.

\section{Experimental Considerations}

\section{Limitations to Immunophenotyping}

The use of immunophenotyping to facilitate the extraction of CSCs from heterogeneous cancer populations was essential for the first validation of the CSC model and has undoubtedly been a critical tool in the search for and characterization of new CSCs. Nonetheless, reliance on surface marker expression as the lone means to purify these cells is not without its limitations. Separation of CSC function from a well-defined immunophenotype, for instance, has been shown in mouse models of leukemia [26••]. In this study, introduction of the HoxA9-Meis1 oncogenic fusion protein drove LSC formation leading to AML initiation. Importantly, using phenotypes normally associated with distinct populations of HSC, primitive progenitors and committed non-self-renewing progenitors, the authors were able to isolate three separate populations of LSC all of which gave rise to each other when transplanted in secondary recipients. The most fascinating aspect of this work is that despite their phenotypic uniqueness, these LSCs shared underlying signaling networks that overlap with leukemic and normal HSC gene signatures. The implication of this mouse model data is that tumor initiation and propagation reflects a cellular state that may be independent of surface marker expression. Indeed, aberrant surface marker expression in human tumors in general complicates direct comparisons of CSC immunophenotypes to normal stem and progenitor cells. This is typified in AML patients with mutated nucleophosmin (NPM), which results in AML with low CD34 expression [27]. Bonnet and colleagues showed that approximately half of tested patient NPM-AMLs had LSC activity in the CD34 ${ }^{-}$ fraction, and in the remaining cases, LSC activity was found in both the $\mathrm{CD} 34^{+}$and $\mathrm{CD} 34^{-}$fractions. The initial demonstration that LSCs are found exclusively in the $\mathrm{CD} 34^{+} \mathrm{CD} 38^{-}$population of human AMLs is considered to be an oversimplification; it is now accepted that LSCs have heterogeneous phenotypes [27-31].

Another technical aspect that could bias identification and assessment of CSC populations is the antibodies used. It has been found that in some cases the reason for the masking of LSC potential in the $\mathrm{CD} 34^{+} \mathrm{CD} 38^{+}$fraction of some human AMLs is recognition of anti-CD38 coated cells and their clearance by the residual innate immune system in NOD-SCID mice [28]. Treating NOD-SCID mice with anti-CD122 antibody to block NK cell activity, using more immune-deficient mouse strains, and injecting cells directly into the bone marrow eliminated the nonleukemia initiating phenotype of some $\mathrm{CD} 38^{+}$cells.

Discrepancies with immunophenotyping CSC populations have also been shown with the surface marker CD133 [32]. The AC133 antibody clone recognizes a glycosylated epitope of CD133 [33] and has been the primary antibody used to identify CSCs in a variety of cancers (Table 1). An important question that is rarely addressed is whether $\mathrm{CD}_{133^{-}}$populations are expressing unglycosylated versions of CD133 or not expressing the protein at all. This was tested in a recent study that examined if AC133 correlated with mRNA and protein expression in a colon CSC model [34]. Intriguingly, they found that expression of CD133 mRNA and protein was unchanged during in vitro differentiation of these cells, but detection by AC133 was only in the undifferentiated CSCs. This work showed that in this context only the glycosylated epitope of CD133 is lost upon CSC differentiation, and at the same time provided important renewed support for CD133, in its glycosylated form, as a CSC marker.

\section{Utility of Xenotransplant Assays in CSC Evaluation}

Mouse strain immunogenicity and the transplant method can impart biases for the ability of transplanted human CSCs to engraft and proliferate. A comparison of cancer growth in NOD-SCID and NSG mice was recently done in AML [35] and pancreatic, non-small cell lung, and head and neck carcinomas [36]. In both studies, limiting dilution assays showed an increase in the TIC frequency with the 
more immune deficient NSG strain; however, both studies demonstrated that regardless of what mouse strain was used, the overall TIC frequency remained low. These studies highlight that for these cancers, growth is controlled by a distinct and rare population of cells and that this does not dramatically change with the mouse model used. On the other hand, there is a profound effect on the frequency of TICs in human melanoma when different mouse strains are used. When $\mathrm{ABCB}^{+}$immunophenotyped populations of human melanoma cells were injected into NOD-SCID mice, the frequency of TICs was estimated to be approximately 1 in $10^{6}$ cells, suggesting this cancer followed the CSC model [37]. This was later challenged by Quintana et al., who showed by using NSG mice, transplanting cells mixed in matrigel and allowing more time for tumor growth to occur, had the TIC frequency increased independent of immunophenotype to 1 in 4 cells [38]. A follow up study by Boiko et al. [39] disputed this, showing CD271 positivity could enrich for human melanoma CSCs when using similar but not identical methods as described in [38]. This was again countered by a study from Quintana et al. [40] demonstrating that neither CD271 nor 21 other differentially expressed surface markers enriched for melanoma TICs. Conflicting results aside, these studies illustrate how important the technical details of the xenotransplant assay are.

While residual immunogenicity of certain mouse strains can, in some cases, obscure productive tumor initiation, other reasons for the inability of these populations to read out in these models could be the absence of essential microenvironmental components and/or growth factors. Recent efforts to create growth factor transgenic immunodeficient mice expressing human GM-CSF, IL-3 and SCF have demonstrated that provision of these human factors can greatly increase the repopulation capacity of transplanted AML cells as well as yield LSC readout in populations that would not elicit leukemic engraftment in NSG alone [41, 42]. As is clear from these studies and those described above, there are many issues that need to be carefully considered in the choice of transplant assay. The method of cell preparation, mouse model selected and even the injection method can be critical to whether a specific cancer will be observed to follow the CSC model.

\section{Emerging Concepts}

\section{Identifying the Cell of Origin in Cancer}

In human cancer it is difficult to determine the identity of the original cell that incurred successive mutations and selection to become tumorigenic. Given the similarities that could be expected to exist between its earliest ancestor and the CSC itself, the importance of determining a CSC's cell of origin as a means of improving its purification should not be underestimated. It appears that in AML, LSCs tend to be isolated from, and share, similar transcriptional programs to their normal HSC and progenitor counterparts [29, 31]. Though this data is consistent with a primitive cell-of-origin model in human AML, definitive proof that transformation consistently occurs in a hematopoietic stem cell, a primitive multipotent progenitor or both has not been shown. In the mouse system, transformation of both hematopoietic stem and progenitor populations into LSCs through the virally-mediated overexpression of known oncogenes has been achieved [43, 44]; however, it is difficult to determine how closely these experimental conditions mirror the oncogenic dose and sequence of events that actually occurs in situ.

Relying on elegant lineage tracing approaches, compelling evidence has been put forth that mouse models of glioblastomas [45], skin papillomas [46] and intestinal adenomas [47••] follow the CSC model. This methodology has also allowed for the demonstration of a likely stem cell origin for tumor initiation in intestinal cancer [47••, 48]. An early event in the development of intestinal cancers is the deletion of the adenomatous polyposis coli (APC) gene, a negative regulator of the Wnt signaling pathway. Using the capacity to delete APC in specific cellular subsets, the Clevers group has demonstrated that when $\operatorname{Lgr}^{+}$crypt stem cells, but not $\mathrm{Lgr}^{-}$differentiated cells, undergo APC deletion and subsequent Wnt activation, large epithelial neoplasms form. Normal intestinal stem cell gene signatures are also prevalent in human intestinal CSCs and this tends to correlate with the degree of malignancy $[49,50]$, but the similarity of normal stem cell and CSC signatures is not always indicative of their lineal relationship. Evidence of this was recently provided in a tour de force of mouse genetics and intestinal tumorigenesis modeling where it was shown that APC deletion and overactive NF- $\kappa$ B signaling in Lgr5 $^{-}$crypt epithelial cells can work synergistically to hyperactivate Wnt signaling and drive tumor formation [51•]. The adenomas that were initiated from non-self renewing $\mathrm{Lgr5}^{-}$cells contained a heterogeneous mix of $\mathrm{Lgr}^{-}$and $\mathrm{Lgr}^{+}$cells, both populations of which were capable of in vivo tumor initiation. This demonstrates that given the appropriate pathway activation, differentiated, non-self renewing cells can give rise to CSCs and importantly, cellular phenotype can change as a result of these alterations. Thus, unless the cellular changes acquired as a result of the initiating mutations are understood, discerning the cell of origin for a given tumor type may provide little additional insight into how the derived CSC might be prospectively identified.

As well as solving an interesting theoretical question, there may be significant therapeutic implication to identifying the 
cell of origin as this could address how similar CSCs are to normal tissue stem cells. For example, if CSCs are derived from mutant clones of normal stem cells there may be a greater likelihood of them retaining features of their normal counterpart such as similar self-renewal programs, phenotype, expression of drug efflux transporters, relative quiescence, resistance to DNA damage and expression of antiapoptotic factors [52]. Understanding if these features are completely conserved during stem cell transformation to CSCs, or if non-stem cell populations that become CSCs selectively acquire all or some of these traits through mutation, selection and convergent evolution are important considerations that will likely shape the effectiveness of future targeted CSC therapies. Interestingly, identifying and exploiting differences between CSCs and normal stem cells has emerged as a feasible anti-cancer strategy [53-58].

Tumor Heterogeneity and Evolution-The Dynamic Nature of CSCs

The prospective isolation of CSCs using the methods outlined in this review (e.g., cell surface marker phenotyping) is particularly subject to the inherent heterogeneity that exists in cancers. Within a specific cancer there is a diversity of different mutations and/or chromosomal aberrations leading to multiple molecular and cytogenetic subtypes of the disease. However, genetic heterogeneity also exists within a patient's tumor or leukemia [59] in the form of genetically distinct clones. Intraclonal genetic heterogeneity and evolution is not a new idea [1]; however, the genomic sequencing technologies to demonstrate it robustly have only recently been developed [60-64]. These studies highlight that within a patient's breast, leukemia, or pancreatic cancer there tends to be a dominant clone comprising the majority of the primary tumor in addition to numerous genetically similar subclones. When examining pancreatic metastasis [61], acute leukemia from myeloid dysplasia [63] or leukemia relapse after chemotherapy [64] the aggressive secondary tumors originated from clones of the primary neoplasm, but had incurred additional mutations which allowed selective growth advantages. Intraclonal heterogeneity was also demonstrated in clear-cell renal carcinoma [65]. When Gerlinger and colleagues biopsied different regions of a patient's primary tumor or metastasis and performed genomic analyses they found about two-thirds of mutations were not shared between regions of the same tumor and that there could be different mutations of the same driver genes in the different regions sampled. Although the CSC hypothesis was not specifically tested in these studies it is possible that CSCs are the culprits for the maintenance of the numerous intratumor clones and are the cells that undergo selection and mutation to establish metastatic and secondary tumors [2].
The merging of intraclonal genetic heterogeneity with the CSC hypothesis was recently espoused by Mel Greaves [2] and is supported by novel experimental work from his lab and that of John Dick's [66•, 67•]. In these studies clonal tracking in human acute lymphoblastic leukemia was performed using multiplex fluorescence in situ hybridization [66•] or genome-wide SNP arrays [67•]. Though different methods were used, both studies showed a branching clonal evolution model where multiple genetic subclones compete for repopulation in tumor xenografts. These findings are supported from earlier work that tested heterogeneity in CSCs through clonal analysis of lentiviral marked patient AML [68]. Hope et al., were the first to demonstrate that AML clones in xenografted mice display varying repopulating activity upon secondary and tertiary transplantation. The differences in repopulation kinetics could have been due to genetic heterogeneity within lentiviral marked clones; however, the requisite genomic techniques to test this were not yet available. Given the likelihood that most lentiviral marked clones were of a single dominant genetic clone [64], it is also possible that non-genetic factors such as epigenetic mechanisms or signals from the microenvironment could have affected repopulation. This idea was recently explored more thoroughly in a xenotransplant model of colorectal cancer [69]. Kreso et al., demonstrated that serial transplantation of colorectal tumor cells did not dramatically change the genomic profile from the primary tumor indicating that tumor clones were stable over in vivo passaging. When they combined this analysis with clonal lentiviral tracking they found that similar to what was seen by Hope et al., there were different lentiviral marked clones that displayed varying tumor initiating capacity upon serial transplantation. The conclusion drawn from these findings was that non-genetic factors could dictate whether a specific clone drives tumorigenesis and in turn contributes to intraclonal heterogeneity. The mounting evidence that CSCs are subject to evolutionary changes and that this is coupled with stochasticity in cell behaviour influenced by intrinsic or extrinsic cues demonstrates that there can be multiple functional CSC subclones within single cancers.

\section{Novel Approaches for Prospective CSC Isolation}

Since their initial discovery, identification and isolation of CSCs has primarily relied on searching for CSCs in subsets of cells that share similar phenotypes with their normal tissue stem cell counterparts. As has been discussed above, this approach fails in situations where these surface markers are not represented on the cell of origin and/or are dysregulated as a result of transforming mutations that occur in the process of CSC generation. Another difficulty 
Fig. 1 Reporters of stemness could facilitate the

identification, isolation and study of CSCs. The top diagram illustrates phenotypic heterogeneity in the bulk tumor cell population. CSCs (green nucleus) have disparate immunophenotypes (with and without dark outline and hexagons) which can result in incomplete isolation of the CSC population with fluorescence activated cell sorting.

Hypothetically, reporters using "stemness" promoters to drive expression of fluorescent proteins, for example, could be used to mark the CSC population as indicated in the middle schematic. A lentivirus engineered to express the reporter could be used to infect human tumor cells, which upon transplantation into mice, could allow for the isolation and study of CSCs. In this case, CSCs are marked by transgene expression (orange). A similar approach, shown at bottom, is the utilization of a transgenic reporter mouse crossed to a mouse cancer model. Aside from the difficulty in identifying what promoter to use for the reporter system, gradients in reporter signal as shown (orange and blue cells) indicate the improbability of identifying a simple binary reporter system

\section{Immunophenotyping CSCs}

Bulk tumor population

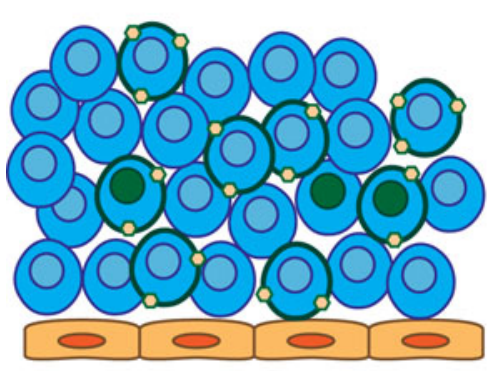

Fluorescence activated cell sorting
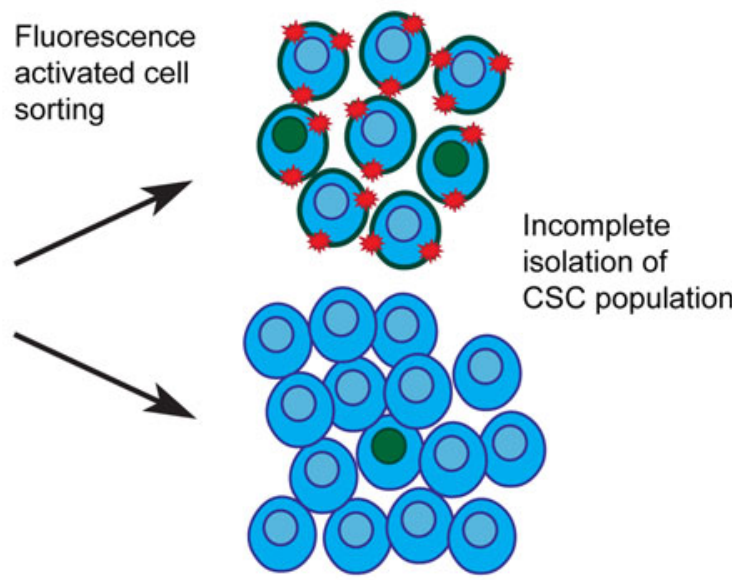

\section{Using reporters to isolate CSCs}

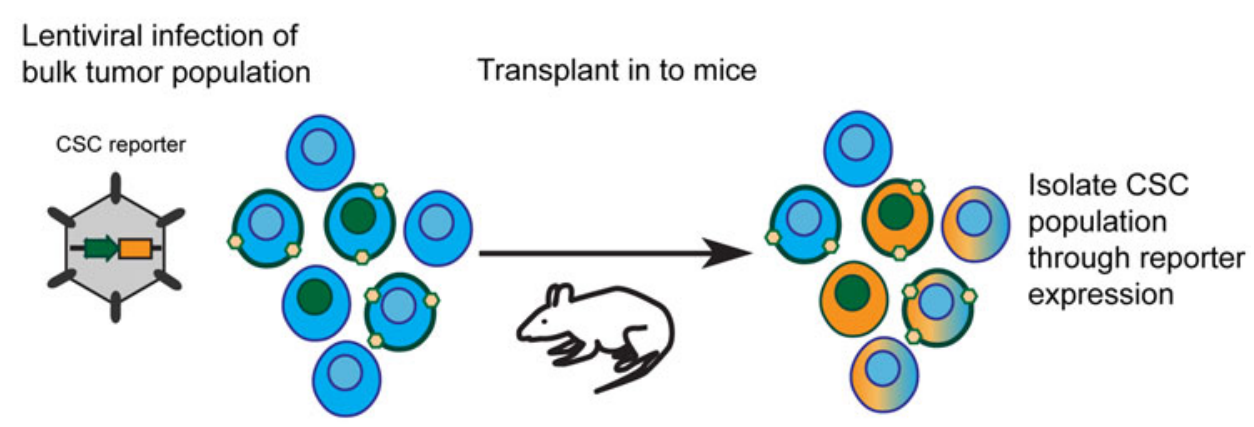

Transgenic mice to model CSCs

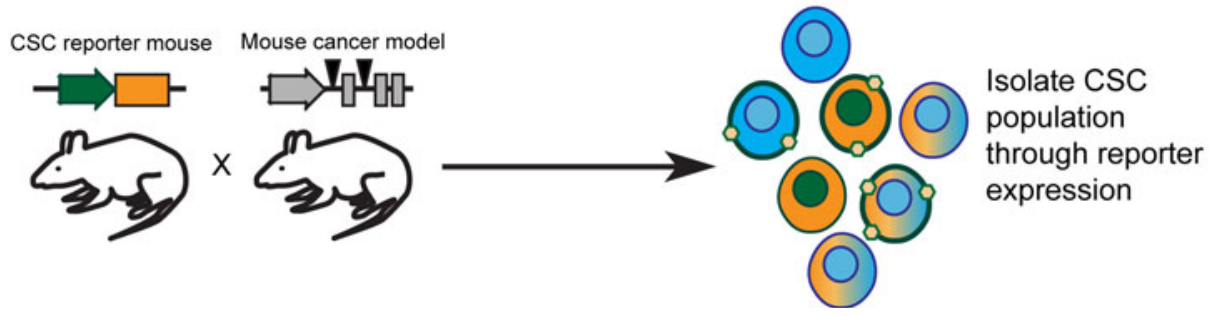

with immunophenotyping is that markers that have been relied on for decades in the purification of normal stem cells are in many cases uncharacterized in terms of their functional contribution to stemness. What are needed are faithful reporters of stem cell behaviour that are maintained regardless of the stage of the disease or passage in culture (Fig. 1). Precedents do exist for the successful use of such reporters in other stem cell types as evidenced by the robust selection for pluripotent cells using the EOS reporter, a lentivector that utilizes promoter and enhancer elements for pluripotency genes including Oct4 to drive GFP [70]. It has also been found using vectors and transgenic mice that report on the activation of Wnt and Notch signaling, respectively, that both pathways are at their most active in HSCs and downregulate as differentiation proceeds [71,
72]. Going forward, this novel approach applied to cancer may offer an alternative and potentially more universal means to separate CSCs. Though few attempts have been made along these lines thus far, recent work by Vermeulen and colleagues demonstrates how successful this approach can be. In this work, the authors utilized a LEF/TCF reporter of Wnt activity in a murine model of APC and K-RAS-induced colon cancer. Despite observing a gradient of Wnt activation across all tumor cells, those cells having high Wnt activity were far more enriched for cells capable of cancer initiation when re-transplanted when compared to the intermediate or low Wnt signaling populations [73•]. In another example, MELK promoter GFP reporter mice have been exploited to show that in MMTV-Wnt1 induced breast tumors, the $\mathrm{GFP}^{+}$populations are uniquely enriched 
for breast CSCs [74]. With the emergence of microRNAs as important regulators of stemness, there have also been efforts to use sensors of their presence as tools to enrich for stem cell populations. In particular, this method has been successfully utilized for the enrichment of human HSCs by detection of the elevated presence of mir-126 [75] and now awaits application to the CSC field. One can also envision the development of reagents that, along the lines of ALDEFLUOR, rely on the detection of CSC-specific enzymes through assays that detect their modification of a known substrate.

\section{Conclusion}

In summary, as the search for CSC-targeted therapies continues to intensify, the ability to prospectively identify and isolate CSCs with high purity will be critical. As a mainstay methodology in this field, surface phenotyping is certainly not obsolete, but will likely benefit in the future from exploring candidate surface markers whose presence or absence is linked to the unique biological function of the CSC and/or in combining this approach with additional reporters of CSC functionality.

Acknowledgments We would like to thank members of the Hope Lab and the Stem Cell and Cancer Research Institute for thoughtful discussion. This work was conducted with the support of the Ontario Institute for Cancer Research through funding provided by the Government of Ontario.

Disclosure S. Rentas, N. Holzapfel and K. Hope declare that they have no conflict of interest.

\section{References}

Papers of particular interest, published recently, have been highlighted:

- Of importance

- Of major importance

1. Nowell PC (1976) The clonal evolution of tumor cell populations. Science 194:23-28

2. Greaves M (2010) Cancer stem cells: back to Darwin? Semin Cancer Biol 20:65-70

3. Dick J (2008) Stem cell concepts renew cancer research. Blood 112:4793-5600

4. Lapidot T, Sirard C, Vormoor J, Murdoch B, Hoang T, CaceresCortes $\mathrm{J}$ et al (1994) A cell initiating human acute myeloid leukaemia after transplantation into SCID mice. Nature 367:645-653

5. Bonnet D, Dick J (1997) Human acute myeloid leukemia is organized as a hierarchy that originates from a primitive hematopoietic cell. Nat Med 3:730-737

6. Al-Hajj M, Wicha MS, Benito-Hernandez A, Morrison SJ, Clarke MF (2003) Prospective identification of tumorigenic breast cancer cells. Proc Natl Acad Sci USA 100:3983-3988
7. Singh SK, Clarke ID, Terasaki M, Bonn VE, Hawkins C, Squire J et al (2003) Identification of a cancer stem cell in human brain tumors. Cancer Res 63:5821-5828

8. Singh SK, Hawkins C, Clarke ID, Squire JA, Bayani J, Hide T et al (2004) Identification of human brain tumour initiating cells. Nature 432:396-401

9. O'Brien CA, Pollett A, Gallinger S, Dick JE (2007) A human colon cancer cell capable of initiating tumour growth in immunodeficient mice. Nature 445:106-110

10. Li C, Heidt DG, Dalerba P, Burant CF, Zhang L, Adsay V et al (2007) Identification of pancreatic cancer stem cells. Cancer Res 67:1030-1037

11. Hermann PC, Huber SL, Herrler T, Aicher A, Ellwart JW, Guba $M$ et al (2007) Distinct populations of cancer stem cells determine tumor growth and metastatic activity in human pancreatic cancer. Cell Stem Cell 1:313-323

12. Prince ME, Sivanandan R, Kaczorowski A, Wolf GT, Kaplan MJ, Dalerba P et al (2007) Identification of a subpopulation of cells with cancer stem cell properties in head and neck squamous cell carcinoma. Proc Natl Acad Sci USA 104:973-978

13. Ma S, Chan KW, Hu L, Lee TK, Wo JY, Ng IO et al (2007) Identification and characterization of tumorigenic liver cancer stem/progenitor cells. Gastroenterology 132:2542-2556

14. Jordan CT, Upchurch D, Szilvassy SJ, Guzman ML, Howard DS, Pettigrew AL et al (2000) The interleukin-3 receptor alpha chain is a unique marker for human acute myelogenous leukemia stem cells. Leukemia 14:1777-1784

15. Goodell MA, Brose K, Paradis G, Conner AS, Mulligan RC (1996) Isolation and functional properties of murine hematopoietic stem cells that are replicating in vivo. J Exp Med 183: 1797-1806

16. Scharenberg CW, Harkey MA, Torok-Storb B (2002) The ABCG2 transporter is an efficient Hoechst 33342 efflux pump and is preferentially expressed by immature human hematopoietic progenitors. Blood 99:507-512

17. Hirschmann-Jax C, Foster AE, Wulf GG, Nuchtern JG, Jax TW, Gobel U et al (2004) A distinct "side population" of cells with high drug efflux capacity in human tumor cells. Proc Natl Acad Sci USA 101:14228-14233

18. Storms RW, Trujillo AP, Springer JB, Shah L, Colvin OM, Ludeman SM et al (1999) Isolation of primitive human hematopoietic progenitors on the basis of aldehyde dehydrogenase activity. Proc Natl Acad Sci USA 96:9118-9123

19. Hess DA, Meyerrose TE, Wirthlin L, Craft TP, Herrbrich PE, Creer $\mathrm{MH}$ et al (2004) Functional characterization of highly purified human hematopoietic repopulating cells isolated according to aldehyde dehydrogenase activity. Blood 104:1648-1655

20. Cheung AM, Wan TS, Leung JC, Chan LY, Huang H, Kwong YL et al (2007) Aldehyde dehydrogenase activity in leukemic blasts defines a subgroup of acute myeloid leukemia with adverse prognosis and superior NOD/SCID engrafting potential. Leukemia 21:1423-1430

21. Ginestier C, Hur MH, Charafe-Jauffret E, Monville F, Dutcher J, Brown $\mathrm{M}$ et al (2007) ALDH1 is a marker of normal and malignant human mammary stem cells and a predictor of poor clinical outcome. Cell Stem Cell 1:555-567

22. Duester G (1996) Involvement of alcohol dehydrogenase, shortchain dehydrogenase/reductase, aldehyde dehydrogenase, and cytochrome $\mathrm{P} 450$ in the control of retinoid signaling by activation of retinoic acid synthesis. Biochemistry 35:12221-12227

23. Duong V, Rochette-Egly C (2011) The molecular physiology of nuclear retinoic acid receptors. From health to disease. Biochim Biophys Acta 1812:1023-1031

24. Langevin F, Crossan GP, Rosado IV, Arends MJ, Patel KJ (2011) Fancd 2 counteracts the toxic effects of naturally produced aldehydes in mice. Nature 475:53-58 
25. Garaycoechea JI, Crossan GP, Langevin F, Daly M, Arends MJ, Patel KJ (2012) Genotoxic consequences of endogenous aldehydes on mouse haematopoietic stem cell function. Nature 489: 571-575

26. • Gibbs KD Jr., Jager A, Crespo O, Goltsev Y, Trejo A, Richard CE et al. (2012) Decoupling of tumor-initiating activity from stable immunophenotype in HoxA9-Meis1-driven AML. Cell Stem Cell 10: 210-7. This work demonstrated that within single murine myeloid leukemias, phenotypically distinct LSCs could be isolated with unique surface marker profiles that upon isolation and re-transplantation gave rise to the all other LSC types. Despite the absence of a unifying phenotype, the authors went on to show that these LSCs shared a common gene expression signature which was, independent of phenotype, a more accurate indicator of their functional capacity

27. Taussig DC, Vargaftig J, Miraki-Moud F, Griessinger E, Sharrock K, Luke T et al (2010) Leukemia-initiating cells from some acute myeloid leukemia patients with mutated nucleophosmin reside in the CD34(-) fraction. Blood 115:1976-1984

28. Taussig DC, Miraki-Moud F, Anjos-Afonso F, Pearce DJ, Allen $\mathrm{K}$, Ridler C et al (2008) Anti-CD38 antibody-mediated clearance of human repopulating cells masks the heterogeneity of leukemia-initiating cells. Blood 112:568-575

29. Eppert K, Takenaka K, Lechman ER, Waldron L, Nilsson B, van Galen P et al (2011) Stem cell gene expression programs influence clinical outcome in human leukemia. Nat Med 17:1086-1093

30. Sarry JE, Murphy K, Perry R, Sanchez PV, Secreto A, Keefer C et al (2011) Human acute myelogenous leukemia stem cells are rare and heterogeneous when assayed in NOD/SCID/IL2Rgammac-deficient mice. J Clin Investig 121:384-395

31. Goardon N, Marchi E, Atzberger A, Quek L, Schuh A, Soneji S et al (2011) Coexistence of LMPP-like and GMP-like leukemia stem cells in acute myeloid leukemia. Cancer Cell 19:138-152

32. Donovan LK, Pilkington GJ (2012) CD133: holy of grail of neuro-oncology or promiscuous red-herring? Cell Prolif 45:527-537

33. Yin AH, Miraglia S, Zanjani ED, Almeida-Porada G, Ogawa M, Leary AG et al (1997) AC133, a novel marker for human hematopoietic stem and progenitor cells. Blood 90:5002-5012

34. Kemper K, Sprick MR, de Bree M, Scopelliti A, Vermeulen L, Hoek M et al (2010) The AC133 epitope, but not the CD133 protein, is lost upon cancer stem cell differentiation. Cancer Res 70:719-729

35. Vargaftig J, Taussig DC, Griessinger E, Anjos-Afonso F, Lister TA, Cavenagh J et al (2012) Frequency of leukemic initiating cells does not depend on the xenotransplantation model used. Leukemia 26:858-860

36. Ishizawa K, Rasheed ZA, Karisch R, Wang Q, Kowalski J, Susky $\mathrm{E}$ et al (2010) Tumor-initiating cells are rare in many human tumors. Cell Stem Cell 7:279-282

37. Schatton T, Murphy GF, Frank NY, Yamaura K, Waaga-Gasser $\mathrm{AM}$, Gasser $\mathrm{M}$ et al (2008) Identification of cells initiating human melanomas. Nature 451:345-349

38. Quintana E, Shackleton M, Sabel MS, Fullen DR, Johnson TM, Morrison SJ (2008) Efficient tumour formation by single human melanoma cells. Nature 456:593-598

39. Boiko AD, Razorenova OV, van de Rijn M, Swetter SM, Johnson DL, Ly DP et al (2010) Human melanoma-initiating cells express neural crest nerve growth factor receptor CD271. Nature 466: 133-137

40. Quintana E, Shackleton M, Foster HR, Fullen DR, Sabel MS, Johnson TM et al (2010) Phenotypic heterogeneity among tumorigenic melanoma cells from patients that is reversible and not hierarchically organized. Cancer Cell 18:510-523

41. Feuring-Buske M, Gerhard B, Cashman J, Humphries RK, Eaves CJ, Hogge DE (2003) Improved engraftment of human acute myeloid leukemia progenitor cells in beta 2-microglobulin-deficient NOD/SCID mice and in NOD/SCID mice transgenic for human growth factors. Leukemia 17:760-763

42. Wunderlich M, Chou FS, Link KA, Mizukawa B, Perry RL, Carroll M et al (2010) AML xenograft efficiency is significantly improved in NOD/SCID-IL2RG mice constitutively expressing human SCF, GM-CSF and IL-3. Leukemia 24:1785-1788

43. Huntly BJ, Shigematsu H, Deguchi K, Lee BH, Mizuno S, Duclos $\mathrm{N}$ et al (2004) MOZ-TIF2, but not BCR-ABL, confers properties of leukemic stem cells to committed murine hematopoietic progenitors. Cancer Cell 6:587-596

44. Krivtsov AV, Twomey D, Feng Z, Stubbs MC, Wang Y, Faber J et al (2006) Transformation from committed progenitor to leukaemia stem cell initiated by MLL-AF9. Nature 442:818-822

45. Chen J, Li Y, Yu TS, McKay RM, Burns DK, Kernie SG et al (2012) A restricted cell population propagates glioblastoma growth after chemotherapy. Nature 488:522-526

46. Driessens G, Beck B, Caauwe A, Simons BD, Blanpain C (2012) Defining the mode of tumour growth by clonal analysis. Nature 488:527-530

47. •- Schepers AG, Snippert HJ, Stange DE, van den Born M, van Es JH, van de Wetering $M$ et al. (2012) Lineage tracing reveals Lgr5 + stem cell activity in mouse intestinal adenomas. Science 337: 730-735. Using a lineage re-tracing technique in a mouse model of intestinal adenoma, this paper demonstrates that only a rare subset of cells in the adenoma marked by Lgr5 positivity, is responsible for giving rise to and propagating the neoplasm. This study was critical in validating the CSC hypothesis in that it did not rely on isolation of these cells and transplantation to read out CSC activity but demonstrated this behaviour without manipulation in vivo

48. Barker N, Ridgway RA, van Es JH, van de Wetering M, Begthel $\mathrm{H}$, van den Born $\mathrm{M}$ et al (2009) Crypt stem cells as the cells-oforigin of intestinal cancer. Nature 457:608-611

49. Dalerba P, Kalisky T, Sahoo D, Rajendran PS, Rothenberg ME, Leyrat AA et al (2011) Single-cell dissection of transcriptional heterogeneity in human colon tumors. Nat Biotechnol 29:1120-1127

50. Merlos-Suarez A, Barriga FM, Jung P, Iglesias M, Cespedes MV, Rossell D et al (2011) The intestinal stem cell signature identifies colorectal cancer stem cells and predicts disease relapse. Cell Stem Cell 8:511-524

51. - Schwitalla S, Fingerle AA, Cammareri P, Nebelsiek T, Goktuna SI, Ziegler PK et al. (2012) Intestinal Tumorigenesis Initiated by Dedifferentiation and Acquisition of Stem-Cell-like Properties. Cell 152: 25-38. In this study, a mouse model of intestinal tumorigenesis utilizing APC deletion and elevated $N F-\kappa B$ showed that with the appropriate synergy of mutations, non-stem cells can be transformed into tumor initiating cells and can in doing so upregulate key indicators of stemness

52. Zhou BB, Zhang H, Damelin M, Geles KG, Grindley JC, Dirks PB (2009) Tumour-initiating cells: challenges and opportunities for anticancer drug discovery. Nat Rev Drug Discov 8:806-823

53. Jin L, Hope KJ, Zhai Q, Smadja-Joffe F, Dick JE (2006) Targeting of CD44 eradicates human acute myeloid leukemic stem cells. Nat Med 12:1167-1174

54. Sachlos E, Risueno RM, Laronde S, Shapovalova Z, Lee JH, Russell J et al (2012) Identification of drugs including a dopamine receptor antagonist that selectively target cancer stem cells. Cell 149:1284-1297

55. Gupta PB, Onder TT, Jiang G, Tao K, Kuperwasser C, Weinberg RA et al (2009) Identification of selective inhibitors of cancer stem cells by high-throughput screening. Cell 138:645-659

56. Jin L, Lee EM, Ramshaw HS, Busfield SJ, Peoppl AG, Wilkinson L et al (2009) Monoclonal antibody-mediated targeting of CD123, IL-3 receptor alpha chain, eliminates human acute myeloid leukemic stem cells. Cell Stem Cell 5:31-42 
57. Majeti R, Chao MP, Alizadeh AA, Pang WW, Jaiswal S, Gibbs $\mathrm{KD}$ Jr et al (2009) CD47 is an adverse prognostic factor and therapeutic antibody target on human acute myeloid leukemia stem cells. Cell 138:286-299

58. Skrtic M, Sriskanthadevan S, Jhas B, Gebbia M, Wang X, Wang $\mathrm{Z}$ et al (2011) Inhibition of mitochondrial translation as a therapeutic strategy for human acute myeloid leukemia. Cancer Cell 20:674-688

59. Greaves M, Maley CC (2012) Clonal evolution in cancer. Nature 481:306-313

60. Nik-Zainal S, Van Loo P, Wedge DC, Alexandrov LB, Greenman $\mathrm{CD}$, Lau KW et al (2012) The life history of 21 breast cancers. Cell 149:994-1007

61. Yachida S, Jones S, Bozic I, Antal T, Leary R, Fu B et al (2010) Distant metastasis occurs late during the genetic evolution of pancreatic cancer. Nature 467:1114-1117

62. Navin N, Kendall J, Troge J, Andrews P, Rodgers L, McIndoo J et al (2011) Tumour evolution inferred by single-cell sequencing. Nature 472:90-94

63. Walter MJ, Shen D, Ding L, Shao J, Koboldt DC, Chen K et al (2012) Clonal architecture of secondary acute myeloid leukemia. N Engl J Med 366:1090-1098

64. Ding L, Ley TJ, Larson DE, Miller CA, Koboldt DC, Welch JS et al (2012) Clonal evolution in relapsed acute myeloid leukaemia revealed by whole-genome sequencing. Nature 481:506-510

65. Gerlinger M, Rowan AJ, Horswell S, Larkin J, Endesfelder D, Gronroos E et al (2012) Intratumor heterogeneity and branched evolution revealed by multiregion sequencing. N Engl $\mathrm{J}$ Med 366:883-892

66. - Anderson K, Lutz C, van Delft FW, Bateman CM, Guo Y, Colman SM et al. (2011) Genetic variegation of clonal architecture and propagating cells in leukaemia. Nature 469: 356-361. In this work, childhood acute lymphoblastic leukemias with intiating ETV6-RUNX1 translocations were studied at the clonal level using multiplexed FISH for additional mutations. This work was critical in demonstrating that unique subclone propagating cells could be identified with distinct genetic abnormalities which was consistent with a branching evolution of CSC over time in these malignancies
67. - Notta F, Mullighan CG, Wang JC, Poeppl A, Doulatov S, Phillips LA et al. (2011) Evolution of human BCR-ABL1 lymphoblastic leukaemia-initiating cells. Nature 469: 362-367. Similar to the study above, this work demonstrated genetic heterogeneity and evolution of LSC in adult BCR-ABL1 lymphoblastic leukemia this time through the use of DNA copy number alteration profiling

68. Hope KJ, Jin L, Dick JE (2004) Acute myeloid leukemia originates from a hierarchy of leukemic stem cell classes that differ in self-renewal capacity. Nat Immunol 5:738-743

69. Kreso A, O'Brien CA, van Galen P, Gan O, Notta F, Brown AM et al (2012) Variable clonal repopulation dynamics influence chemotherapy response in colorectal cancer. Science 339:543-548

70. Hotta A, Cheung AY, Farra N, Vijayaragavan K, Seguin CA, Draper JS et al (2009) Isolation of human iPS cells using EOS lentiviral vectors to select for pluripotency. Nat Methods 6:370-376

71. Reya T, Duncan AW, Ailles L, Domen J, Scherer DC, Willert K et al (2003) A role for Wnt signalling in self-renewal of haematopoietic stem cells. Nature 423:409-414

72. Duncan AW, Rattis FM, DiMascio LN, Congdon KL, Pazianos $\mathrm{G}$, Zhao $\mathrm{C}$ et al (2005) Integration of Notch and Wnt signaling in hematopoietic stem cell maintenance. Nat Immunol 6:314-322

73. - Vermeulen L, De Sousa EMF, van der Heijden M, Cameron K, de Jong JH, Borovski T et al. (2010) Wnt activity defines colon cancer stem cells and is regulated by the microenvironment. Nat Cell Biol 12: 468-476. This paper is one of the first to utilize a strategy of prospective isolation of CSC populations through the application of a reporter of stem-cell specific signaling. Specifcally a reporter of Wnt activity was used to show that in mouse colon cancer, only the population of cells with high Wht activity was enriched for CSCs

74. Hebbard LW, Maurer J, Miller A, Lesperance J, Hassell J, Oshima RG et al (2010) Maternal embryonic leucine zipper kinase is upregulated and required in mammary tumor-initiating cells in vivo. Cancer Res 70:8863-8873

75. Lechman ER, Gentner B, van Galen P, Giustacchini A, Saini M, Boccalatte FE et al (2012) Attenuation of miR-126 activity expands HSC in vivo without exhaustion. Cell Stem Cell 11:799-811 